\title{
ИССЛЕДОВАНИЕ ХАРАКТЕРИСТИК И МИНЕРАЛЬНОГО СОСТАВА ТОРФА ТОМСКОЙ ОБЛАСТИ ПРИМЕНИТЕЛЬНО К ЭНЕРГЕТИЧЕСКОМУ ИСПОЛЬЗОВАНИЮ
}

\author{
Ибраева Канипа Талгатовна', \\ kti1@tpu.ru
}

\author{
Манаев Юрий Олегович', \\ Okia53007@yandex.ru
}

\author{
Табакаев Роман Борисович', \\ TabakaevRB@tpu.ru
Языков Николай Алексеевич², yazykov@catalysis.ru

\author{
Заворин Александр Сергеевич', \\ zavorin@tpu.ru \\ 1 Национальный исследовательский Томский политехнический университет, \\ Россия, 634050, г. Томск, пр. Ленина, 30. \\ 2 Институт катализа им. Г.К. Борескова СО РАН, \\ Россия, 630090, г. Новосибирск, пр. Академика Лаврентьева, 5.
}

Актуальность исследования обуславливается перспективностью вовлечения возобновляемой биомассы (в частности, торфа) в использование для выработки тепловой и электрической энергии. Это позволит частично решить проблему ресурсодефицитных регионов, зависящих от поставок топлива с разрабатываемых угольных месторождений.

Цель: исследование теплотехнических характеристик и минеральной части торфа ряда крупных месторождений Томской области для оценки возможности их энергетического использования.

Объект. Рассмотрены пробы низинного торфа с месторождений Суховское и Аркадьевское, а также с одного из месторождений Томского района.

Методы. Теплотехнические характеристики исследуемых проб были определены согласно ГОСТ Р 55661-2013, 33503-2015, 55660-2013. Значения теплоты сгорания установлены при помощи калориметра АБК-1 (РЭТ, Россия), элементный состав - на анализаторе Vario Micro Cube (Elementar, Германия). Исследование состава минеральной части торфа проводили методом рентгенофлуоресцентного анализа с использованием спектрометра EDX-720-P (Shimadzu, Япония), а также методом рентгеновской дифрактометрии с использованием дифрактометра Shimadzu XRD7000 (СUК -излучения) со счетчиком монохроматора Shimadzи СМ-3121. Характерные температуры плавкости золы определяли согласно ГОСТ 2057-94. Структуру рассматриваемых проб исследовали методом сканирующей микроскопии на электронном микроскопе TM 3000 (Hitachi, Япония).

Результаты. На основе полученных результатов можно заключить, что использование околотомского торфа для сжигания камерным способом нецелесообразно из-за высокого выхода золы. Однако этот ресурс может быть рассмотрен как минеральное удобрение в сельском хозяйстве благодаря наличию таких элементов, как фосфор, калий. Высокое содержание карбонатов указывает на возможность использования околотомского торфа в качестве добавки к высокосернистым углям для снижения выбросов оксида серы SO . Характеристики суховского и аркадьевского торфа позволяют рассматривать их в качестве альтернативы привозному топливу. Преимуществами для энергетического использования является малое содержание серы, следствием которого будут минимальные вредные выбросы при сжигании. Более того, наличие большого количества карбонатов может способствовать полному связыванию SO при сжигании торфа. Предпочтительным способом энергетического использования торфа с месторождений Томской области является его сжигание в кипящем слое.

\section{Ключевые слова:}

Топливо, торф, минеральная часть, сжигание, энергетическое использование.

\section{Введение}

Постепенное исчерпание ресурсов традиционных органических топлив и необходимость снижения вредных выбросов от энергетических объектов заставляют задуматься об использовании биомассы, к которой относят отходы сельскохозяйственной деятельности, животноводства, лесной промышленности, торф и др. Биомасса является возобновляемым источником энергии, при сжигании которого не происходит усиление глобального парникового эффекта $[1,2]$. В связи с этим в последние годы в мире прослеживается тенденция увеличе- ния доли использования биомассы для выработки тепловой и электрической энергии [3-7].

Для Российской Федерации особый интерес представляет вовлечение торфяных ресурсов в топливно-энергетический баланс. Это обусловлено тем, что Россия располагает обширными залежами торфа - более 185 млрд т [8, 9], что делает нашу страну лидером по количеству запасов этого сырья. Основная часть торфяных месторождений сосредоточена в Западно-Сибирском регионе: в Тюменской области расположено свыше $50 \%$ его ресурсов, в Томской - около $26 \%$ [9]. При этом торф 
относится к возобновляемым природным ресурсам, темпы прироста которого опережают объемы его промышленного использования [10]. В свою очередь, наличие столь колоссальных запасов при отсутствии их промышленной разработки приводит к периодическому возникновению природных пожаров [11-13], что также указывает на необходимость вовлечения торфа в энергетику. Однако, несмотря на перечисленные преимущества, в нашей стране торф всё еще остается малоиспользуемым топливным ресурсом.

Опыт других стран показывает, что торф может играть заметную роль для тепло- и энергоснабжения. Например, в Ирландии на основе торфа вырабатывается 5,30 \% от общего количества производства энергии, в Финляндии - 4,54 \%, в Белоруссии $-1,85 \%$ [14].

Согласно энергетической стратегии России до 2030 года [15], доля использования торфа в топливно-энергетическом балансе торфодобывающих регионов должна составлять не менее 8-10\%. Это позволит частично решить проблему ресурсодефицитных регионов, зависящих от поставок топлива с разрабатываемых угольных месторождений.

Однако сдерживающим фактором достижения заявленных показателей до сих пор остаются высокие эксплуатационные издержки энергетического использования торфа в качестве топлива. Торф характеризуется высокой влажностью, что в свою очередь ведет за собой большие затраты на сушку перед его сжиганием. Кроме того, наличие влаги затрудняет перевозку и разгрузку топлива: в зимний период торф смерзается, а в летний период слеживается [16]. Из-за неоднородного гранулометрического состава торфа наблюдается высокая доля провала через колосниковую решетку при слоевом сжигании [17]. Вдобавок к этому возникает проблема образования шлакозоловых отложений (шлакование поверхностей нагрева), обусловленных особенностями минералогического состава топлива [18].

В качестве альтернативы традиционному сжиганию могут быть рассмотрены технологии предварительной переработки торфа в энергетически более ценные продукты, такие как газообразное, жидкое или твердое композитное топливо [19-22]. Однако в некоторых случаях [23] высокая зольность торфа требует технико-экономического обоснования необходимости его переработки, так как не происходит существенного увеличения теплотехнических характеристик.

Повышение эффективности сжигания и переработки торфа требует изучения широкого спектра его характеристик. В настоящее время изученность торфяных ресурсов Томской области невысока [24], что не позволяет в полной мере оценить перспективы их использования в качестве энергетического сырья.

Это приводит к необходимости подробного изучения как теплотехнических характеристик конкретных месторождений Томской области, так и их минеральной части, от которой, как известно [25], зависят практически все показатели топлива, в том числе и склонность к шлакованию.

Целью настоящей работы является исследование теплотехнических характеристик и минеральной части торфа ряда крупных месторождений Томской области для оценки возможности их энергетического использования.

\section{Методика исследования}

Объект исследования. В качестве объектов исследования были рассмотрены пробы низинного торфа с месторождений Суховское и Аркадьевское, а также с одного из месторождений Томского района. Месторождения находятся вблизи города Томска, что позволяет рассматривать их в качестве стратегического топлива для замены привозного каменного и бурого углей.

Теплотехнические характеристики. Теплотехнические характеристики исследуемых проб были определены согласно ГОСТ Р 33503-2015, ГОСТ 11306-2013, ГОСТ Р 55660-2013. Значения теплоты сгорания и элементный состав торфа установлены при помощи калориметра АБК-1 (РЭТ, Россия) и анализатора Vario Micro Cube (Elementar, Германия) соответственно.

Результаты определения характеристик пересчитывали с учетом содержания диоксида углерода карбонатов, установленного ускоренным объемным методом согласно ГОСТ 13455-91.

Анализ элелентов минеральной части. Исследование состава минеральной части торфа проводили методом рентгенофлуоресцентного анализа с использованием спектрометра EDX-720-P (Shimadzu, Япония). Предварительно пробы торфа измельчали до размера фракций 0,2-1,0 мм, после чего спрессовывали в брикеты цилиндрической формы размерами 50×10 мм по способу [26].

Перед началом анализа спектрометр предварительно калибровался по стандартному образцу (ЛГ58) и чистым химическим веществам, спрессованным в виде таблеток: $\mathrm{CaCO}_{3}, \mathrm{KNO}_{3}, \mathrm{NaNO}_{3}, \mathrm{Mg}$. После калибровки спектрометр поверялся по стандартному образцу 1303. Состав перечисленных стандартных образцов приведен в табл. 1.

Таблица 1. Паспортные значения стандартных образиов (массовая доля элементов в процентах)

Table 1. Passport values of standard samples (mass fraction of elements in percent)

\begin{tabular}{|c|c|c|c|c|c|c|c|c|}
\hline $\begin{array}{c}\text { Индекс C0* } \\
\text { Index SS }\end{array}$ & $\mathrm{Si}$ & $\mathrm{Mn}$ & $\mathrm{P}$ & $\mathrm{Ni}$ & $\mathrm{Cu}$ & $\mathrm{Cr}$ & $\mathrm{Al}$ & $\mathrm{Fe}$ \\
\hline 1303 & 0,21 & 3,04 & 0,077 & 1,19 & 58,3 & - & 0,92 & - \\
\hline ЛГ58 & 0,292 & 0,99 & 0,0135 & 4,26 & 0,388 & 23,4 & - & 67,01 \\
\hline
\end{tabular}

*- индекс стандартного образиа.

* - standard sample index.

Исследование минеральной части проб торфа также проведено методом рентгеновской дифрактометрии с использованием дифрактометра Shimadzu XRD7000 (CuK $\alpha$-излучения) со счетчиком монохроматора Shi- 


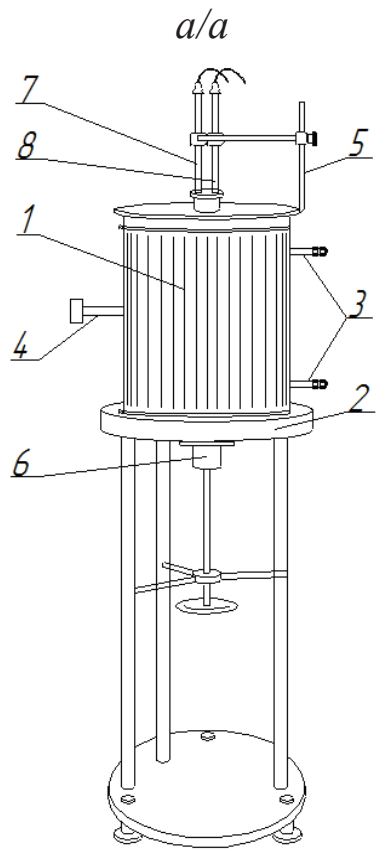

$\sigma / b$

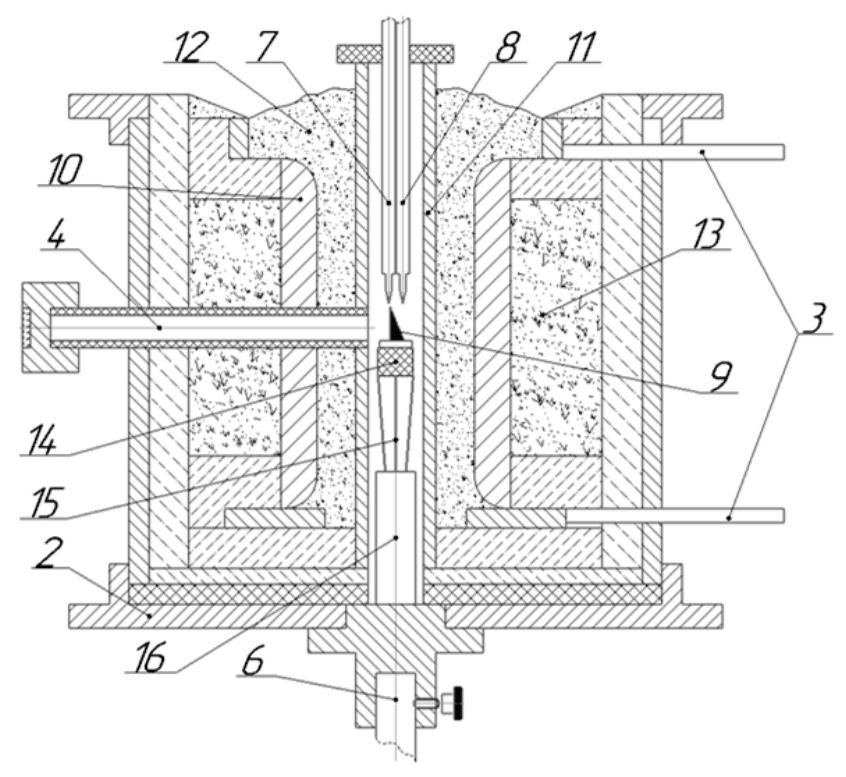

Pис. 1. Эксперилентальная установка: а) общий вид установки; б) продольный разрез печи: 1 - криптоловая печь; 2 - основание печи с подставкой; 3 - тоководы; 4 -визирная трубка; 5 - кронштейн для терлопары; 6 - шток с винтом; 7 - терлопара, введенная в печь; 8 - контрольная терлопара; 9 - пиралидальный образец; 10 - жаровой иилиндр; 11-жаровая труба; 12 - криптоловая засыпка; 13 - шамотная крошка; 14 - керамический столик; 15 - керамические стержни; 16 - угольная подставка

Fig. 1. Experimental setup: a) general view of the setup; b) longitudinal section of the furnace: 1 is the kryptol furnace; 2 is the furnace base stand; 3 are the current conductors; 4 is the aiming tube; 5 is the conduit support bracket; 6 is the rod with screw; 7 is the thermocouple introduced into the furnace; 8 is the control thermocouple; 9 is the pyramidal sample; 10 is the fire cylinder; 11 is the firetube; 12 are the kryptol chips; 13 are the fireclay chips; 14 is the ceramic table; 15 are the ceramic rods; 16 is the coal stand

madzu CM-3121. Качественный рентгеновский анализ осуществлен при помощи базы данных PDF2+.

Определение характерных телператур плавкости золь. Характерные температуры плавкости золы определяли согласно ГОСТ 2057-94. Предварительно из зольного остатка изготавливали образец в форме трехгранной пирамиды. Золу измельчали, смешивали с $10 \%$-ым раствором декстрина в дистиллированной воде до состояния однородной массы. Полученную смесь выкладывали в специально изготовленную форму для затвердевания. Затем застывшую пирамиду извлекали из формы и размещали на платиновой пластине. При определении характерных температур плавкости золы пластину с пирамидой помещали в печь (рис. 1).

Печь - 1 с расположенными внутри пирамидами - 9 нагревали до температуры $1500{ }^{\circ} \mathrm{C}$ со скоростью $10-15{ }^{\circ} \mathrm{C}$ в минуту. Максимальная температура нагрева печи ограничена диапазоном работы контрольной термопары ПП-1 (рис. 1, поз. 8). Измерение температуры в зоне расположения пирамид осуществляли при помощи термопары - 7 градуировки ВР-1 в комплекте с высокоточным ампервольтметром PC500а (Япония) и контрольной термопары - 8 ПП-1 в комплекте с мультиметром Щ 4313 (Россия). Температуру холодных концов перечисленных термопар измеряли при помощи термометра 902 C (Китай) с термопарой ХА для снижения погрешности их измерения.
При нагреве пирамиды - 9 происходит постепенное изменение её формы, описывающееся тремя стадиями деформации: начало деформации $\left(t_{A}\right)$, размягчение $\left(t_{B}\right)$ и переход в жидкоплавкое состояние $\left(t_{c}\right)$. В процессе эксперимента регистрируются температуры, при которых наблюдаются изменения, характерные для каждой из стадий.

Изучение структуры образиов торфа. Структуру рассматриваемых проб исследовали методом сканирующей микроскопии на электронном микроскопе TM 3000 (Hitachi, Япония).

\section{Результаты исследования}

Значения теплотехнических характеристик исследуемых образов, доведенных до воздушно-сухого состояния, приведены в табл. 2. Видно, что исследуемые образцы имеют высокую зольность, значения которой находятся в интервале $A^{d}=22,8-32,6 \%$. Эти значения превышают среднюю величину зольности $(12 \%)$ для торфа, находящегося на территории России [27]. Похожие характеристики по параметру зольности имеют торфяные месторождения Светлогорское $\left(A^{d}=24,4\right)$ и Витебское $\left(A^{d}=25,0\right)$, расположенные в Республике Беларусь [28]. Высокое значение зольности обуславливает низкое значение теплоты сгорания изучаемых образцов торфа, равное $Q_{i}^{r}=7,6-11,8$ МДж/кг. Выход летучих веществ находится в пределах $V^{d a f}=62,9-70,7 \%$, что свидетельствует о высокой 
реакционной способности при сжигании и термической нестабильности торфа. Нелетучий остаток, полученный после определения выхода летучих, имеет порошкообразный вид.

Таблица 2. Теплотехнические характеристики исходного торфа Table 2. Thermotechnical characteristics of the initial peat

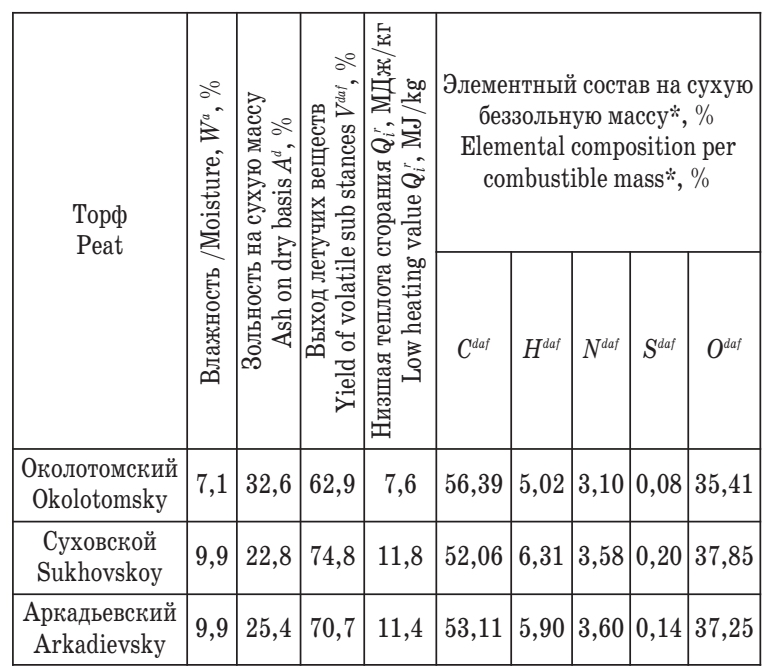

Примечание: * - результаты әлементного состава топлива приведены с учетом содержащегося в топливе диоксида углерода карбонатов $\left(\mathrm{CO}_{2}\right)^{d}$ и гидратной воды, значение которой согласно ГОСТ 27313-2015 принято равным 0,1А . Ввиду малого содержа ния серы поправка на образование сульфатов при разложении карбонатов не учитывалась.

Note: * - the results of fuel elemental composition are given taking into account carbon dioxide carbonates $\left(\mathrm{CO}_{2}\right)^{d}$ contained in the fuel, and hydrated water, the value of which according to SS 27313-2015 is taken to be 0,1 $A^{d}$. Due to the low sulphur content, the correction for sulphate formation was not taken into account in decomposition of carbonates.

\section{Элементный состав минеральной части торфа}

В ходе анализа определены химические элементы в неорганической части торфа. Основные золообразующие макроэлементы - $\mathrm{Si}, \mathrm{Ca}, \mathrm{Fe}, \mathrm{Mg}, \mathrm{K}, \mathrm{Al}$, P. Как можно заметить из табл. 3, наибольшее содержание среди макроэлементов наблюдается у кальция $(\mathrm{Ca}=6,7-15,82 \%)$, а содержание калия и фосфора относительно мало (не превышает 0,4 \%). Основываясь на данных, приведенных в работе [29], в составе минеральной части твердого топлива наиболее распространены такие минералы, как силикаты $\left(\mathrm{Al}_{4}\left[\mathrm{Si}_{4} \mathrm{O}_{10}\right](\mathrm{OH})_{8}\right)$, кварц $\left(\mathrm{SiO}_{2}\right)$, карбонаты $\left(\mathrm{CaCO}_{3}, \mathrm{MgCO}_{3}, \mathrm{FeCO}_{3}\right)$, сульриды $\left(\mathrm{FeS}_{2}\right)$ и др. В связи с этим можно предположить, что кальций и магний представлены минеральной формой карбонатов $\mathrm{CaCO}_{3}$ и $\mathrm{MgCO}_{3}$, а кремний - в виде оксида.

Таблица 3. Содержание элемента в минеральной части в исследуемых образиах

Table 3. Element content in mineral part in the samples

\begin{tabular}{|c|c|c|c|c|c|c|c|}
\hline \multirow{2}{*}{$\begin{array}{c}\text { Исследуемые образцы } \\
\text { торфа } \\
\text { Peat samples }\end{array}$} & \multicolumn{6}{|c|}{ Содержание элемента/Element content } \\
\cline { 2 - 7 } & \multirow{2}{*}{ K, ppm } & $\mathrm{Ca}$ & $\mathrm{Mg}$ & $\mathrm{P}$ & $\mathrm{Si}$ & $\mathrm{Fe}$ & $\mathrm{Al}$ \\
\cline { 3 - 7 } & & \multicolumn{5}{|c|}{$\%$} \\
\hline Околотомский/Okolotomsky & 242,13 & 15,82 & 1,58 & 0,29 & 0,58 & 0,28 & 0,39 \\
\hline Суховской/Sukhovskoy & 263,57 & 7,99 & 1,88 & 0,40 & 0,57 & 0,84 & 0,32 \\
\hline Аркадьевский/Arkadyevsky & 413,54 & 6,7 & 1,38 & 0,20 & 1,95 & 0,44 & 0,55 \\
\hline
\end{tabular}

Для определения основных групп минералов, присутствующих в торфе, использовали метод рентгенофазового анализа [30]. На дифрактограмме (рис. 2) видны пики, характерные для карбоната кальция $\left(\mathrm{CaCO}_{3}\right)$ и оксида кремния $\left(\mathrm{SiO}_{2}\right)$, что подтверждает некоторые ранее сделанные предположения по составу минеральной части.

a) (a)

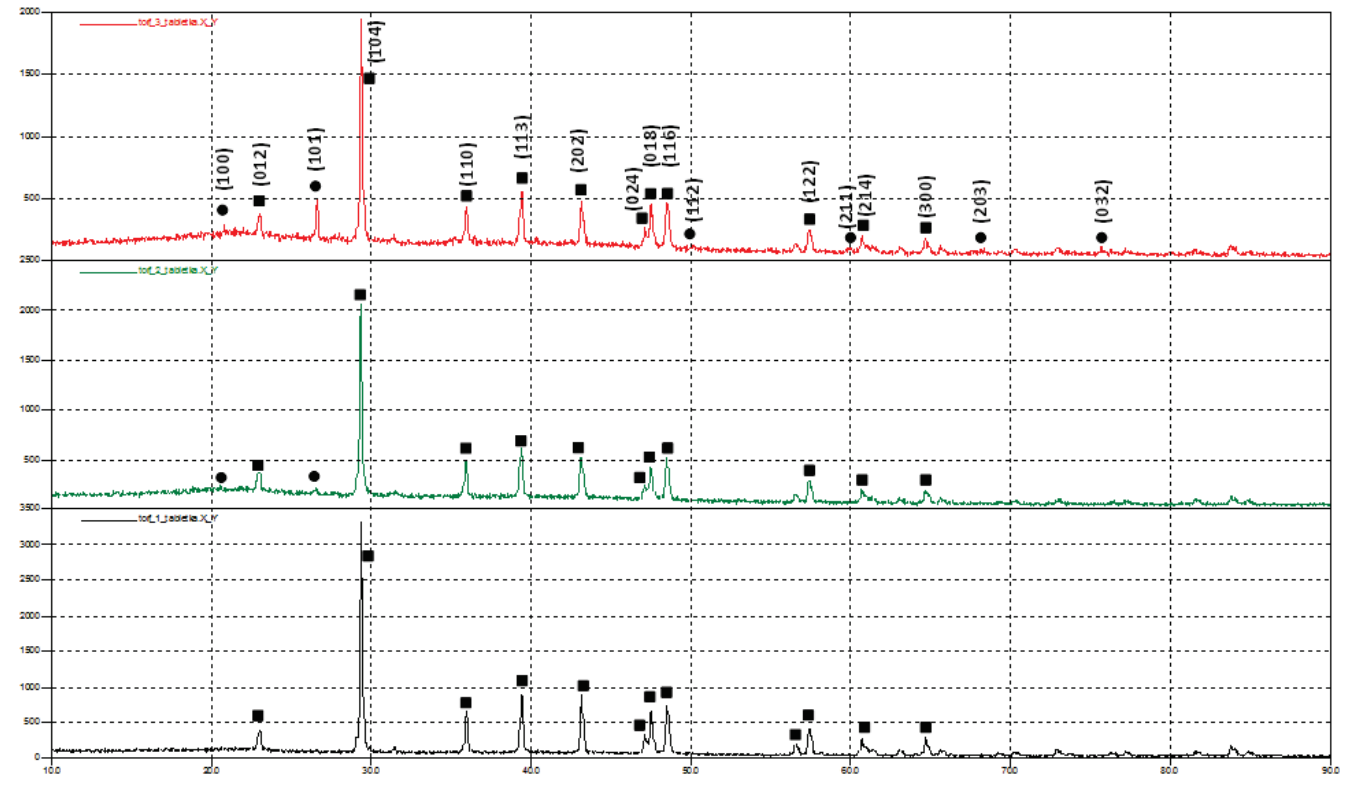

CaCO3 - rhombohedral Space group R-3c No. 167 (ICDD card No. 86-2334) database PDF 2

$\mathrm{SiO}_{2}$ - triclinic Space group P1 No. 1 (ICDD card No. 77-1060) database PDF 2

Рис. 2. Результаты рентгенофазового анализа исследуемых образиов: а) аркадьевский торф; б) суховской торф;в) околотомский торф

Fig. 2. Results of $x$-ray phase analysis of the samples: a) arkadyevsky peat; $b$ ) sukhovskoy peat; $c$ ) okolotomsky peat 
Установленные ускоренным методом величины содержания диоксида углерода карбонатов $\left(\mathrm{CO}_{2}\right)^{d}$ составили для околотомского торфа 20,69\%, суховского торфа - 9,82\%, аркадьевского - 9,11 \% (в пересчете на сухую массу исходного сырья). Учитывая, что карбонаты присутствуют в основном в виде карбоната кальция (рис. 2), на основе полученных значений выхода диоксида углерода массовую долю карбоната кальция в сухой массе пробы можно вычислить по формуле, \% :

$$
\mathrm{CaCO}_{3}^{d}=\left(\mathrm{CO}_{2}\right)^{d} \frac{M_{\mathrm{CaCO}_{3}}}{M_{\mathrm{CO}_{2}}},
$$

где $\mathrm{M}_{\mathrm{CaCO}_{3}}$ - молекулярная масса карбоната кальция, г/моль; $M_{\mathrm{CO}_{2}}$ - молекулярная масса диоксида углерода, г/моль.

Согласно проведенному расчету по формуле (1), получены следующие содержания карбоната кальция: околотомский торф - 47,1\%; суховской торф - 22,3\%; аркадьевский торф - 20,7\%. Столь высокие значения содержания карбоната кальция говорят о возможности связывания оксидов серы при сжигании. Как известно [31], наиболее распространенные методы сероочистки проводят с применением известняковой технологии. Это связано с тем, что известняк $\left(\mathrm{CaCO}_{3}\right)$ является наиболее дешевым сорбентом. Например, в работе [32] показано, что в мировой практике из эксплуатируемых очистных установок 80 \% составляют «мокрые» скрубберы, 72 \% из которых используют в качестве сорбента известняк.

Общую величину минеральной части торфа согласно ГОСТ 27313-2015 можно оценить по формуле:

$$
\begin{gathered}
M M^{d}= \\
=A^{d}+\left(\mathrm{CO}_{2}\right)^{d}+W_{M M}^{d}+0,625 S_{p}^{d}-2,5\left(S_{A}^{d}-S_{\mathrm{SO}_{4}}^{d}\right),
\end{gathered}
$$

где $W_{M M}^{d}$ - гидратная влага, $\% ; S_{p}^{d}-$ пиритная сера, $\% ; S_{A}^{d}-$ сера, связанная в зольном остатке, $\%$; $\mathrm{S}_{\mathrm{SO}_{4}}^{d}$ - сульфатная сера, \%

Согласно ГОСТ 27313-2015, содержание гидратной влаги можно оценить как

$0,1 \cdot A^{a}$. Поскольку значение серы при пересчете на сухое состояние очень мало, то при расчете доли минеральной части рассматриваемых проб составляющие $S_{p}^{d}, S_{A}^{d}, S_{\mathrm{SO}_{4}}^{d}$ не учитывались.

Рассчитанная по формуле (2) массовая доля минеральной массы для околотомского торфа составляет $56,55 \%$, суховского торфа - 34,9\%, аркадьевского торфа - 37,05 \%. Наиболее высокая эффективность сжигания столь высокозольных топлив (минеральная масса более 34 \% ) может быть получена при использовании технологий кипящего слоя [33]. Это достигается за счет активной циркуляции частиц топлива, обеспечивая такие преимущества как экологичность, высокая эффективность сжигания и теплообмена.

\section{Характеристики плавкости золы}

Для оценки поведения неорганической части топлива при сжигании, как правило, применяют метод определения температурных характеристик золы.

Состав и характеристики плавкости золы торфа представлены в табл. 4. Видно, что зола суховского торфа достигает только стадии начала деформации $\left(t_{A}\right)$, а зола околотомского и аркадьевского не претерпевает изменений при температуре до 1480 ${ }^{\circ} \mathrm{C}$. Это связано с особенностью состава минеральной массы торфа: основная часть золы состоит из соединений $\mathrm{SiO}_{2}$ и $\mathrm{CaO}$, которые, как известно $[34,35]$, имеют температуру плавления 1713 и $2580{ }^{\circ} \mathrm{C}$, соответственно.

Высокое содержание $\mathrm{CaO}\left(30,3\right.$ и $48,4 \%$ ) и $\mathrm{SiO}_{2}$ $(21,4$ и $22,2 \%)$ у аркадьевского и околотомского торфа может являться причиной повышенного износа поверхностей нагрева при сжигании. Наличие окислов железа (до $12,1 \%$ ), магния, алюминия и титана может привести к повышенной шлакующей способности торфа [36]. Однако, оценивая результаты определения характеристик плавкости, можно отметить, что изучаемая зола имеет тугоплавкий характер, не слипается при высоких температурах. В процессе сжигания торфа её удаление не составит затруднений [37].

\begin{tabular}{|c|c|c|c|c|c|c|c|c|c|}
\hline \multirow[t]{2}{*}{$\begin{array}{c}\text { Пробы } \\
\text { торфа } \\
\text { Peat samples }\end{array}$} & \multicolumn{3}{|c|}{$\begin{array}{c}\text { Температура } \\
\text { начала дефор- } \\
\text { мации золы, }{ }^{\circ} \mathrm{C} \\
\text { Ash melting } \\
\text { point, }{ }^{\circ} \mathrm{C}\end{array}$} & \multicolumn{6}{|c|}{$\begin{array}{c}\text { Состав золы, \% } \\
\text { Ash composition, \% }\end{array}$} \\
\hline & $t_{A}$ & & $t_{C}$ & $\mathrm{SiO}_{2}$ & $\mathrm{Al}_{2} \mathrm{O}_{3}+\mathrm{TiO}_{2}$ & $\mathrm{FeO}$ & $\mathrm{SO}_{3}$ & $\mathrm{CaO}$ & $\mathrm{MgO}$ \\
\hline $\begin{array}{c}\text { Околотом- } \\
\text { ский } \\
\text { Okolotomsky }\end{array}$ & $>1480$ & \multirow{3}{*}{\multicolumn{2}{|c|}{ 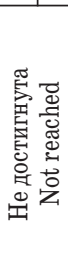 }} & 22,2 & 0,3 & 4,4 & 3,7 & 48,4 & 4,2 \\
\hline $\begin{array}{c}\text { Суховской } \\
\text { Sukhovskoy }\end{array}$ & 1448,3 & & & 4,1 & 7,7 & 12,1 & 1,3 & 32,4 & 1,2 \\
\hline $\begin{array}{c}\text { Аркадьев- } \\
\text { ский } \\
\text { Arkadyevsky }\end{array}$ & $>1480$ & & & 21,4 & 7,2 & 7,3 & 1,6 & 30,3 & 2,4 \\
\hline
\end{tabular}

таблица 4. Состав и характеристики плавкости золь торфа

Table 4. Composition and ash fusion characteristics of peat

\section{Структура образцов торфа}

Торф является полидисперсной системой, в которую входят макро- и микроструктуры (рис. 3). Видно, что макроструктура представлена компонентами неразложившихся остатков растенийторфообразователей. Минеральная часть имеет как приносной, так и сросшийся с органическим веществом характер. Последнее, скорее всего, вызвано процессами метаморфического преобразования торфа.

По своей природе микроструктура в торфе коагуляционная, эти структуры эластичны и подвижны, взаимодействие осуществляется через молекулы и прослойки воды.

\section{Заключение}

В данной работе изучено несколько проб торфа с месторождений, находящихся в географической близости от города Томска. Изученные пробы име- 


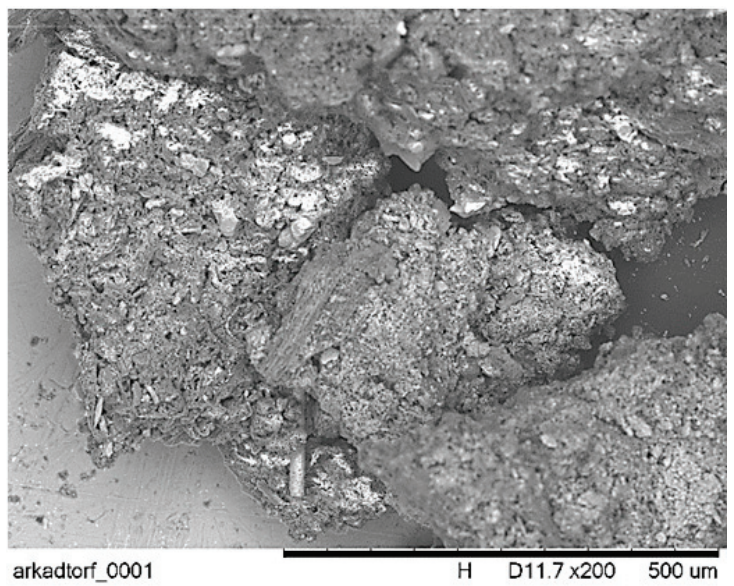

$a / a$

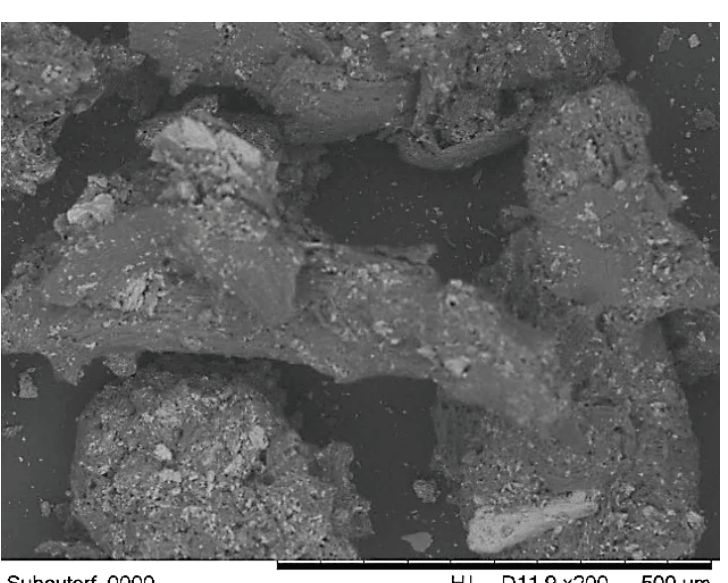

$\sigma / b$
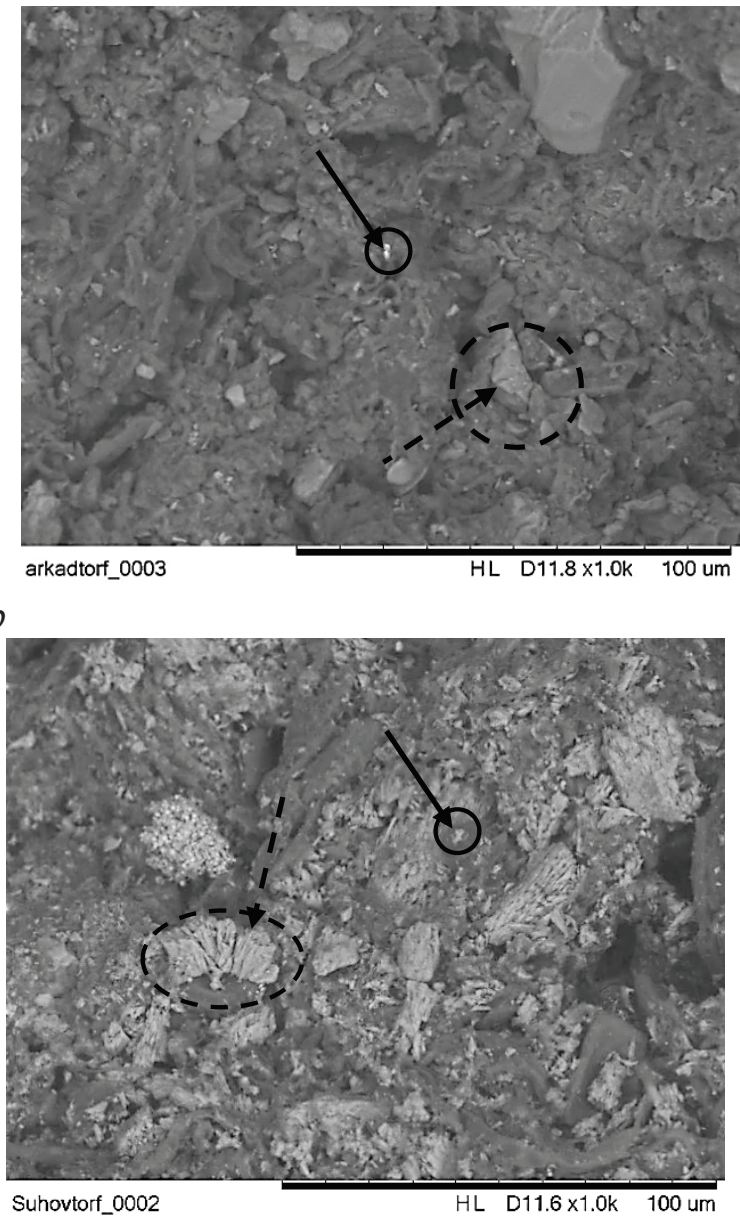

$B / c$
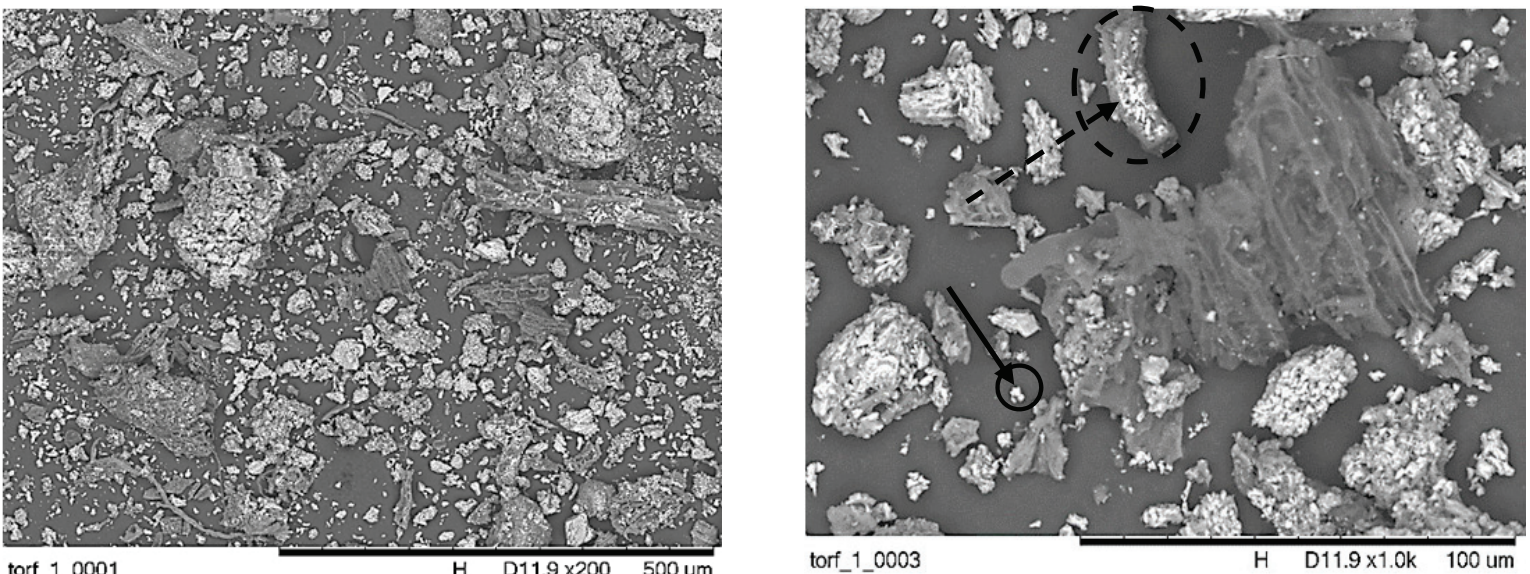

-_--г минеральная примесь, имеющая сросшийся характер

—— механически распределённые по поверхности топлива минеральные включения

Рис. 3. Результаты структурного анализа исследуемых проб торфа при увеличении $200^{x}$ и $1000^{x}$ : а) аркадьевский торф; б) суховской торф; в) околотолский торф

Fig. 3. Results of structural analysis of the studied peat samples: a) arkadyevsky peat; b) sukhovskoy peat; c) okolotomsky peat 
ют высокое значение зольности (более $22 \%$ ), не характерное для большинства торфяных месторождений России. Столь высокая доля балласта обуславливает низкое значение теплоты сгорания рассматриваемых образцов торфа (менее 11,8 МДж/кг) даже в доведенном до воздушно-сухого состоянии.

Установлено, что минеральная часть рассматриваемых проб в основном представлена карбонатом кальция $\left(\mathrm{CaCO}_{3}\right)$ и оксидом кремния $\left(\mathrm{SiO}_{2}\right)$, которые являются основными золообразующими компонентами. Доля карбоната кальция в минеральной части для околотомского торфа составила $-47,1 \%$, суховского торфа - 22,3\% , аркадьевского торфа - 20,7 \% .

По результатам определения состава и характеристик плавкости золы можно заключить, что зола торфа состоит в основном из соединений $\mathrm{CaO}$ и $\mathrm{SiO}_{2}$. Тугоплавкий характер золы свидетельствует о том, что в процессе сжигания торфа её удаление не составит затруднений. Вместе с тем высокое содержание такого прочного минерала как кварц говорит о возможности абразивного износа конвективных поверхностей нагрева.

На основе полученных результатов можно заключить, что использование околотомского торфа для сжигания нецелесообразно из-за высокого содержания золы. Однако этот ресурс может быть рассмотрен в виде минерального удобрения в сельском хозяйстве благодаря наличию таких элементов, как фосфор и калий. Высокое содержание карбоната кальция указывает на возможность использования околотомского торфа в качестве добавки к

\section{СПИСОК ЛИТЕРАТУРЫ}

1. An overview of the composition and application of biomass ash. Part 1. Phase-mineral and chemical composition and classification / S.V. Vassilev, D. Baxter, L.K. Andersen, C.G. Vassileva // Fuel. - 2013. - № 105. - P. 40-76.

2. Abbasi T., Abbasi S.A. Biomass energy and the environmental impacts associated with its production and utilization // Renewable and Sustainable Energy Reviews. - 2010. - V. 14. - № 3. P. 919-937.

3. O'Rourke F., Boyle F., Reynolds A. Renewable energy resources and technologies applicable to Ireland // Renewable and Sustainable Energy Reviews. - 2009. - V. 13. - P. 1975-1984.

4. Ермоленко Г.В. и др. Справочник по возобновляемой энергетике европейского союза. - М.: Институт энергетики НИУ ВШЭ, 2016. -96 c.

5. Kleineidam P., Dörr J. Renewable power generation 2015: the latest World-Market Status // Renewable Energy Focus. - 2015. V. 16. - № 5-6. - P. 160-163.

6. A historical review of promotion strategies for electricity from renewable energy sources in EU countries / R. Haas, C. Panzer, G. Resch, M. Ragwitz, G. Reece, A. Held // Renewable and Sustainable Energy Reviews. - 2011. - V. 15. - № 2. P. 1003-1034

7. Fortov V.E., Popel' 0.S. The current status of the development of renewable energy sources worldwide and in Russia // Thermal engineering. - 2014. - V. 61. - P. 389-398.

8. Торфяные ресурсы Томской области и пути их использования в строительстве / Л.В. Касицкая, Ю.С. Саркисов, Н.П. Горленко, Н.О. Копаница, А.И. Кудяков. - Томск: Изд-во STT, 2007. $-292 \mathrm{c}$ высокосернистым углям для снижения выбросов оксида серы $\mathrm{SO}_{\mathbf{x}}$.

Характеристики суховского и аркадьевского торфа позволяют рассматривать их в качестве альтернативы привозному топливу. В этом случае преимуществом для энергетического использования является малое содержание серы, следствием которого будут минимальные вредные выбросы при сжигании. Более того, наличие большого количества карбоната кальция может способствовать практически полному связыванию $\mathrm{SO}_{\text {x }}$ при сжигании торфа этих месторождений.

Низкая теплота сгорания образцов торфа с месторождений Томской области, обусловленная высоким значением зольности, и состав минеральной части указывают на то, что сжигание в топочных устройствах камерного типа будет сопровождаться такими сложностями, как механический недожог и эрозионный износ. Опыт эффективного сжигания высокозольного топлива показывает, что предпочтительным способом энергетического использования такого торфа является сжигание в кипящем слое.

Исследование профинансировано Российским фондом фундаментальных исследований (РФФИ) в рамках проекта № 18-38-00648. Экспериментальные исследования проведены в Томском политехническом университете при поддержке Министерства науки и высшего образования Российской Федерации (ГЗ «Наука» № 13.13269.2018/8.9 и ВИУ-НОЦ И.Н. Бутакова-296/2018). Аналитические измерения выполнены в ралках государственного задания Института катализа СО РАН.

9. Торфяные ресурсы Томской области и их использование / Л.И. Инишева, В.С. Архипов, С.Г. Маслов, Л.С. Михантьева. - Новосибирск: б. и., 1995. -85 с.

10. Колотушкин В.И. Справочная книжка торфяника. - М.: Недра, 1973. $-208 \mathrm{c}$.

11. Effects of peat fires on the characteristics of humic acid extracted from peat soil in Central Kalimantan, Indonesia / Yustiawati, Y. Kihara, K. Sazawa et al. // Environmental Science and Pollution Research. - 2015. - V. 22. - № 4. - P. 2384-2395.

12. Григорьев А. Лесные и торфяные пожары 2002 года // Лесн. бюллетень. - 2003. - № 21-22. - С. 11.

13. Zaidel'man F.R. The problem of fire control on drained peatlands and its solution // Eurasian Soil Science. - 2011. - V. 44. № 8. - P. 919-926.

14. Боярко Г.Ю., Бернатонис П.В., Бернатонис В.К. Торфяная промышленность России и мира. Анализ состояния и перспективы развития // Минеральные ресурсы России. Экономика и управление. - 2014. - № 6. - С. 56-61.

15. Энергетическая стратегия России на период до 2030 года. Утв. распоряжением Правительства РФ от 13 ноября 2009 г. № 1715 p. $-144 \mathrm{c}$.

16. Transportation of coal concentrates at negative ambient temperatures / A.D. Uchitel', M.V. Kormer, V.P. Lyalyuk, I.A. Lyakhova, E.0. Shmel'tser, Yu.I. Vititnev // Coke and Chemistry. 2013, - V. 56. - № 5. - P. 167-172.

17. Contamination and Corrosion of the Boiler Steam Superheaters at Thermal Power Stations Incinerating Solid Domestic Wastes and Biomass / E.N. Zelikov, G.A. Ryabov, E.P. Dik, A.N. Tugov // Thermal Engineering. - 2008. - V. 55. - № 11. P. 978-983. 
18. Чернецкий М.Ю., Дектерев А.А., Бурдуков А.П. Расчетное исследование факельного горения мелкодисперсного лигноцеллюлозного сырья // Журнал Сибирского федерального университета. Серия: техника и технологии. - 2013. - № 6. C. $625-636$.

19. TG-FTIR-MS study of pyrolysis products evolving from peat / J. Yang, H. Chen, W. Zhao, J. Zhou // Journal of Analytical and Applied Pyrolysis. - 2016. - № 117. - P. 296-309.

20. Tcvetkov P., Strizhenok A. Ecological and economic efficiency of peat fast pyrolysis projects as an alternative source of raw energy resources // Journal of Ecological Engineering. - 2016. V. 17. - № 1. - P. 56-62. DOI: 10.12911/22998993/61190

21. Biomass Pyrolysis and Gasification Comprehensive Modeling for Effective Power Generation at Combined Cycle Power Plant / A. Fedyukhin, I. Sultanguzin, A. Gyul'maliev, V. Sergeev // Eurasian Chemico-Technological Journal. - 2017. - V. 19. P. 245-253.

22. Thermal processing of biomass into high-calorific solid composite fuel / R. Tabakaev, I. Shanenkov, A. Kazakov, A. Zavorin // Journal of Analytical and Applied Pyrolysis. - 2017. D0I: 10.1016/j.jaap.2017.02.016

23. Табакаев Р.Б., Казаков А.В., Заворин А.С. Перспективность низкосортных топлив Томской области для теплотехнологического использования // Известия Томского политехнического университета. - 2013. - Т. 323. - № 4. - С. 41-46.

24. Бернатонис П.В., Боярко Г.Ю., Бернатонис В.К. Эффективность разработки торфяных месторождений Томской области в современных условиях // Вестник Томского государственного университета. - 2011. - № 334. - С. 195-199.

25. Алехнович А.Н. Влияние минеральной части на показатели и характеристики энергетических углей // Энергетик. - 2008. № 3. - C. 8-13.

26. Possible directions for using bran in heat-power engineering M. Gaydabrus, I. Razov, R. Tabakaev, V. Lebedev // MATEC Web of Conferences. - 2017. - V. 110. - № 01030. D0I: $10.1051 /$ matecconf $/ 201711001030$

27. Энергетическое топливо СССР. Ископаемые угли, горючие сланцы, торф, мазут и горючий природный газ: справочник /
В.С. Вдовченко, М.И. Мартынова, Н.В. Новицкий, Г.Д. Юшина. - М.: Энергоатомиздат, 1991. - 183 с.

28. Лис Л.С. и др. Торфяные месторождения Республики Беларусь, пригодные для комплексного освоения на ближайшую и отдаленную перспективу. - Минск: Беларуская навука, 2013. -115 c.

29. Залкинд И.Я., Вдовченко В.С., Дик Э.П. Зола и шлаки в котельных топках. - М.: Энергоатомиздат, 1998. - 80 с.

30. Magnetite hollow microspheres with a broad absorption bandwidth of $11.9 \mathrm{GHz}$ : Toward promising lightweight electromagnetic microwave absorption / I. Shanenkov, A. Sivkov, A. Ivashutenko, V. Zhuravlev, Q. Guo, L. Li, G. Li, G. Wei, W. Han // Physical Chemistry Chemical Physics. - 2017. - V. 19. - № 30. P. 19975-19983.

31. Жабо В.В. Охрана окружающей среды на ТЭС и АЭС. - М.: Энергоатомиздат, $1992 .-240 \mathrm{c}$.

32. Применение методики термодинамической оценки воздействия известняковой технологии мокрой сероочистки газов на объекты окружающей среды / А.М. Касимов, Т.В. Козуля, Д.И. Емельянова, М.М. Козуля // Экология и промышленность. - 2016. - № 1. - С. 94-98.

33. Исследования сжигания твердого топлива в низкотемпературном кипящем слое с определением выбросов токсических веществ / Ю.А. Безносик, В.А. Логвин, К.А. Коринчук, Д.А. Киржнер // Химическая промышленность. - 2014. T. 9. - № 1. - C. 15-19.

34. Рахманкулов М.М., Паращенко В.М. Технология литья жаропрочных сплавов. - М.: Интермет Инжиниринг, 2000. - 464 с.

35. Рабинович В.А., Хавин 3.Я. Краткий химический справочник. - Л.: Химия, 1977. - 72 с.

36. Алехнович А.Н. Шлакование пылеугольных энергетических котлов. - М.: НТФ «Энергопрогресс», 2013. - 116 с.

37. Хзмалян Д.М. Теория горения и топочные устройства. - М.: Энергия, 1976. - 484 с.

Поступила 09.11.2018 2.

\section{Информация об авторах}

Ибраева K.T., аспирант научно-образовательного центра И.Н. Бутакова Томского политехнического университета.

Манаев Ю.О., студент научно-образовательного центра И.Н. Бутакова Томского политехнического университета.

Tабакаев P.Б., кандидат технических наук, научный сотрудник И.Н. Бутакова Томского политехнического университета.

Языков $\boldsymbol{H . A . , ~ к а н д и д а т ~ т е х н и ч е с к и х ~ н а у к , ~ н а у ч н ы и ̆ ~ с о т р у д н и к ~ л а б о р а т о р и и ~ к а т а л и т и ч е с к и х ~ п р о ц е с с о в ~ п е р е - ~}$ работки возобновляемого сырья Института катализа им. Г.К. Борескова СО РАН.

Заворин A.C., доктор технических наук, профессор научно-образовательного центра И.Н. Бутакова Томского политехнического университета. 


\title{
RESEARCH OF CHARACTERISTICS AND MINERAL COMPOSITION OF PEAT OF THE TOMSK REGION RELATING TO ENERGY USE
}

\author{
Kanipa T. Ibraeva', \\ kti1@tpu.ru \\ Yuri O. Manaev', \\ Okia53007@yandex.ru \\ Roman B. Tabakaev', \\ TabakaevRB@tpu.ru \\ Nikolay A. Yazykov², \\ yazykov@catalysis.ru
}

\author{
Alexander S. Zavorin', \\ zavorin@tpu.ru \\ 1 National Research Tomsk Polytechnic University, \\ 30, Lenin avenue, Tomsk, 634050, Russia. \\ 2 Boreskov Institute of Catalysis SB RAS, \\ 5, Acad. Lavrentiev avenue, Novosibirsk, 630090, Russia.
}

The relevance of the research is caused by the need to involve renewable biomass (in particular, peat) to generate heat and electrical energy. This will partially solve the problem of resource-deficient regions, depending on the supply of fuel from developed coal deposits. The main aim of the research is the investigation of thermal characteristics and the mineral matter of the peat of a number of large deposits of the Tomsk region to assess the possibility of their energy use.

objects of researches are the samples of low-moor peat from Sukhovskoye and Arkadyevskoye deposits and one of the Tomsk region deposits.

Methods. Thermal characteristics of the studied samples were determined according to GOST 33503-2015 (ISO 11722:2013), 55661-2013 (ISO 1171:2010), 55660-2013 (ISO 562:2010). Net calorific values of the peats were determined in the ABK-1 calorimeter (Russia), the elemental composition of the organic matter was determined using the analyzer Vario Micro Cube (Elementar, Germany). Peat mineral matter composition was studied by X-ray fluorescence analysis using an EDX-720-P spectrometer (Shimadzu, Japan) as well as by X-ray diffractometry using a Shimadzu XRD7000 diffractometer (CUK -radiation) with a Shimadzu CM-3121 monochromator counter. Typical ash melting points were determined according to GOST 2057-94 (ISO 540-81). The structure of the samples under study was examined by scanning electron microscopy using a TM 3000 electron microscope (Hitachi, Japan).

Results. On the basis of the obtained results, it can be concluded that, due to the high ash content, the use of okolotomsky peat for chamber-type combustion is impractical. However, this resource can be considered as a mineral fertilizer in agriculture due to the presence of such elements as phosphorus, potassium. The high content of carbonates indicates the possibility of its using as an additive to high-sulfur coal to reduce emissions of sulfur oxide SOx. The characteristics of sukhovskoy and arkadyevsky peat make it possible to consider them as an alternative to imported fuel. The preferred method of energy use of peat from Tomsk region fields is its combustion in a fluidized bed.

\section{Key words:}

Fuel, peat, mineral matter, combustion, energy use.

The research was funded by the Russian Foundation for Basic Research (RFBR) in the framework of project No. 18-38-00648. The experiments were carried out at Tomsk Polytechnic University with the support of the Ministry of Science and Higher Education of the Russian Federation (State assignment «Science» No. 13.13269.2018 / 8.9 and the VIU-SEC of I.N. Butakova-296/2018). Analytical measurements were carried out within the framework of the budget project for Boreskov Institute of Catalysis.

\section{REFERENCES}

1. Vassilev S.V., Baxter D., Andersen L.K., Vassileva C.G. An overview of the composition and application of biomass ash. P. 1. Phase-mineral and chemical composition and classification. Fuel, 2013, no. 105, pp. 40-76.

2. Abbasi T., Abbasi S.A. Biomass energy and the environmental impacts associated with its production and utilization. Renewable and Sustainable Energy Reviews, 2010, vol. 14, no. 3, pp. 919-937.

3. O'Rourke F., Boyle F., Reynolds A. Renewable energy resources and technologies applicable to Ireland. Renewable and Sustainable Energy Reviews, 2009, vol. 13, pp. 1975-1984.
4. Ermolenko G.V. Spravochnik po vozobnovlyaemoy energetike evropeyskogo soyuza [Handbook of renewable energy of the European Union]. Moscow, Institut energetiki NIU VShE Publ., 2016. $96 \mathrm{p}$.

5. Kleineidam P., Dörr J. Renewable power generation 2015: the latest World-Market Status. Renewable Energy Focus, 2015, vol. 16 , no. 5-6, pp. 160-163.

6. Haas R., Panzer C., Resch G., Ragwitz M., Reece G., Held A. A historical review of promotion strategies for electricity from renewable energy sources in EU countries. Renewable and Sustainable Energy Reviews, 2011, vol. 15, no. 2, pp. 1003-1034. 
7. Fortov V.E., Popel' O.S. The current status of the development of renewable energy sources worldwide and in Russia. Thermal engineering, 2014, vol. 61, pp. 389-398.

8. Kasitskaya L.V., Sarkisov Yu.S., Gorlenko N.P., Kopanitsa N.O., Kudyakov A.I. Torfyanye resursy Tomskoy oblasti i puti ikh ispolzovaniya $v$ stroitelstve [Peat resources of Tomsk region and ways of their use in construction]. Tomsk, STT Publ., 2007. $292 \mathrm{p}$.

9. Inisheva L.I., Arkhipov V.C., Maslov S.G., Mikhanteva L.S. Tor fyanye resursy Tomskoy oblasti i ikh ispolzovanie [Peat resources of Tomsk region and their use]. Novosibirsk, $1995.85 \mathrm{p}$.

10. Kolotushkin V.I. Spravochnaya knizhka torfyanika [Peatland reference book]. Moscow, Nedra Publ., 1973. 208 p.

11. Yustiawati, Kihara Y., Sazawa K. Effects of peat fires on the characteristics of humic acid extracted from peat soil in Central Kalimantan, Indonesia. Environmental Science and Pollution Research, 2015, vol. 22, no. 4, pp. 2384-2395.

12. Grigorev A. Forest and peat fires in 2002. Forest Bulletin, 2004, no. 21-22, pp. 11. In Rus.

13. Zaidel'man F.R. The problem of fire control on drained peatlands and its solution. Eurasian Soil Science, 2011, vol. 44, no. 8, pp. 919-926.

14. Boyarko G.Yu., Bernatonis P.V., Bernatonis V.K. Peat industry of Russia and the world. Analysis of the state and development prospects. Mineral resources of Russia. Economics and Management, 2014, no. 6, pp. 65-75. In Rus.

15. Energeticheskaya strategiya Rossii na period do 2030 goda [Russia's energy strategy for the period up to 2030. Approved Decree of the Government of the Russian Federation of November 13, 2009 No. 1715 p.] 144 p.

16. Uchitel' A.D., Kormer M.V., Lyalyuk V.P., Lyakhova I.A., Shmel'tser E.0., Vititnev Yu.I. Transportation of coal concentrates at negative ambient temperatures. Coke and Chemistry, 2013, vol. 56, no. 5, pp. 167-172.

17. Zelikov E.N., Ryabov G.A., Dik E.P., Tugov A.N. Contamination and Corrosion of the Boiler Steam Superheaters at Thermal Power Stations Incinerating Solid Domestic Wastes and Biomass. Thermal Engineering, 2008, vol. 55, no. 11, pp. 978-983.

18. Chernetsky M.Y., Dekterev A.A., Burdukov A.P. Numerical research of pulverized combustion of micro-grinded lignocellulose raw materials. Journal of Siberian Federal University, 2013, no. 6, pp. 625-636. In Rus.

19. Yang J., Chen H., Zhao W., Zhou J. TG-FTIR-MS study of pyrolysis products evolving from peat. Journal of Analytical and $A p$ plied Pyrolysis, 2016, no. 117, pp. 296-309.

20. Tcvetkov P., Strizhenok A., Ecological and economic efficiency of peat fast pyrolysis projects as an alternative source of raw energy resources. Journal of Ecological Engineering Volume, 2016, vol. 17 , no. 1, pp. 56-62.

21. Fedyukhin A., Sultanguzin I., Gyul'maliev A., Sergeev V. Biomass pyrolysis and gasification comprehensive modeling for effective power generation at combined cycle power plant. Eurasian Chemico-Technological Journal, 2017, vol. 19, pp. 245-253.

22. Tabakaev R., Shanenkov I., Kazakov A., Zavorin A. Thermal processing of biomass into high-calorific solid composite fuel. Journal of Analytical and Applied Pyrolysis, 2017. D0I: 10.1016/j.jaap.2017.02.016

23. Tabakaev R.B., Kazakov A.V., Zavorin A.S. The prospects of lowgrade fuels of Tomsk region for thermal technology use. Bulletin of the Tomsk Polytechnic University, 2013, vol. 323, no. 4, pp. 41-46. In Rus.

24. Bernatonis P.V., Boyarko G.Yu., Bernatonis V.K. The effectiveness of the development of peat deposits of Tomsk region in modern conditions. Bulletin of Tomsk State University, 2011, no. 334, pp. 195-199. In Rus.

25. Alekhnovich A.N. The influence of the mineral part on the performance and characteristics of power coals. Energetic, 2008, no. 3, pp. 8-13. In Rus.

26. Gaydabrus M., Razov I., Tabakaev R., Lebedev V. Possible directions for using bran in heat-power engineering. MATEC Web of Conferences, 2017, vol. 110, no. 01030. D0I: $10.1051 /$ matecconf $/ 201711001030$

27. Vdovchenko V.S., Martynova M.I., Novitskiy N.V., Yushina G.D. Energeticheskoe toplivo SSSR. Iskopaemye ugli, goryuchie slantsy, torf, mazut i goryuchiy prirodny gaz: spravochnik [Power fuel of the USSR. Fossil coals, oil shale, peat, fuel oil and combustible natural gas: a guide]. Moscow, Energoatomizdat Publ., 1991. 183 p.

28. Lis L.S. Torfyanye mestorozhdeniya Respubliki Belarus, prigodnye dlya kompleksnogo osvoeniya na blizhayshuyu i otdalennuyu perspektivu [Peat deposits of the Republic of Belarus, suitable for complex development in the near and long term]. Minsk, Belaruskaya navuka Publ., 2013. 115 p.

29. Zalkind I.Ya., Vdovchenko V.S., Dik E.P. Zola $i$ shlaki v kotelnykh topkakh [Ash and slag in boiler furnaces]. Moscow, Energoatomizdat Publ., $1998.80 \mathrm{p}$.

30. Shanenkov I., Sivkov A., Ivashutenko A., Zhuravlev V., Guo Q., Li L., Li G., Wei G., Han W. Magnetite hollow microspheres with a broad absorption bandwidth of $11.9 \mathrm{GHz}$ : Toward promising lightweight electromagnetic microwave absorption. Physical Chemistry Chemical Physics, 2017, vol. 19, no. 30, pp. 19975-19983.

31. Zhabo V.V. Okhrana okruzhayushchey sredy na TES i AES [Environmental protection in the TPP and NPP]. Moscow, Energoatomizdat Publ., $1992.240 \mathrm{p}$.

32. Kasimov A.M., Kozulya T.V., Emelyanova D.I., Kozulya M.M. Application of methods of thermodynamic estimation of influence of technology of wet desulfurization of limestone by gases on objects of environment. Ecology and industry, 2016, no. 1, pp. 94-98. In Rus.

33. Beznosik Yu.A., Logvin V.A., Korinchuk K.A., Kirzhner D.A. Research of solid fuel combustion in low-temperature fluidized bed with determination of toxic substances emissions. Chemical industry, 2014, vol. 9, no. 1, pp. 15-19. In Rus.

34. Rakhmankulov M.M., Parashchenko V.M. Tekhnologiya litya zharoprochnykh splavov [Technology of casting superalloys]. Moscow, Intermet Engineering Publ., 2000. 464 p.

35. Rabinovich V.A., Khavin Z.Ya. Kratkiy khimicheskiy spravochnik [Brief Chemical Reference]. Saint Petersburg, Khimiya Publ., 1977. $72 \mathrm{p}$.

36. Alekhnovich A.N. Shlakovanie pyleugolnykh energeticheskikh kotlov [Slagging of pulverized coal energy boilers]. Moscow, NTF Energoprogress Publ., 2013. 116 p.

37. Khzmalyan D.M. Teoriya goreniya i topochnye ustroystva [Theory of combustion and combustion devices]. Moscow, Energiya Publ., 1976. $484 \mathrm{p}$.

Received: 09 November 2018.

\section{Information about the authors}

Kanipa T. Ibraeva, graduate student, National Research Tomsk Polytechnic University.

Yuri O. Manaev, student, National Research Tomsk Polytechnic University.

Roman B. Tabakaev, researcher, Cand. Sc., National Research Tomsk Polytechnic University.

Nikolay A. Yazykov, researcher, Cand. Sc., Boreskov Institute of Catalysis SB RAS.

Alexander S. Zavorin, Dr. Sc., professor, National Research Tomsk Polytechnic University. 